\title{
The FoxO3/type 2 deiodinase pathway is required for normal mouse myogenesis and muscle regeneration
}

\author{
Monica Dentice, ${ }^{1}$ Alessandro Marsili, ${ }^{2}$ Raffaele Ambrosio, ${ }^{3}$ Ombretta Guardiola, ${ }^{4}$ \\ Annarita Sibilio, ${ }^{1}$ Ji-Hye Paik, ${ }^{5}$ Gabriella Minchiotti, ${ }^{4}$ Ronald A. DePinho, ${ }^{5}$ \\ Gianfranco Fenzi, ${ }^{1}$ P. Reed Larsen, ${ }^{2}$ and Domenico Salvatore ${ }^{1,6}$
}

\begin{abstract}
'Department of Molecular and Clinical Endocrinology and Oncology, University of Naples "Federico II," Naples, Italy. ${ }^{2}$ Thyroid Section, Division of Endocrinology, Diabetes and Hypertension, Brigham and Women's Hospital and Harvard Medical School, Boston, Massachusetts, USA. ${ }^{3}$ RCCS Fondazione SDN, Naples, Italy. ${ }^{4}$ Stem Cell Fate Laboratory, Institute of Genetics and Biophysics "A. Buzzati-Traverso," CNR, Naples, Italy. ${ }^{5}$ Belfer Institute for Applied Cancer Science, Departments of Medical Oncology, Medicine and Genetics, Dana-Farber Cancer Institute, Harvard Medical School, Boston, Massachusetts, USA. ${ }^{6}$ CEINGE-Biotecnologie Avanzate s.c. a r.l., Naples, Italy.
\end{abstract}

\begin{abstract}
The active thyroid hormone $3,5,3^{\prime}$ triiodothyronine (T3) is a major regulator of skeletal muscle function. The deiodinase family of enzymes controls the tissue-specific activation and inactivation of the prohormone thyroxine (T4). Here we show that type 2 deiodinase (D2) is essential for normal mouse myogenesis and muscle regeneration. Indeed, D2-mediated increases in T3 were essential for the enhanced transcription of myogenic differentiation $1(M y O D)$ and for execution of the myogenic program. Conversely, the expression of T3-dependent genes was reduced and after injury regeneration markedly delayed in muscles of mice null for the gene encoding D2 (Dio2), despite normal circulating T3 concentrations. Forkhead box O3 (FoxO3) was identified as a key molecule inducing D2 expression and thereby increasing intracellular T3 production. Accordingly, FoxO3-depleted primary myoblasts also had a differentiation deficit that could be rescued by high levels of T3. In conclusion, the FoxO3/D2 pathway selectively enhances intracellular active thyroid hormone concentrations in muscle, providing a striking example of how a circulating hormone can be tissue-specifically activated to influence development locally.
\end{abstract}

\section{Introduction}

The active thyroid hormone 3,5,3' triiodothyronine (T3) derives either directly from thyroid secretion or by the monodeiodination of the prohormone thyroxine (T4) by one of two iodothyronine selenodeiodinases. Type 1 deiodinase is expressed in the liver, kidney, and thyroid but not skeletal muscle of vertebrates, and $\mathrm{T} 3$ produced from $\mathrm{T} 4$ by this enzyme is largely released into the plasma. On the other hand, type 2 deiodinase (D2) is specifically expressed in the central nervous system, pituitary, thyroid gland, brown adipose tissue, retina, and skeletal muscle. Much of the T3 derived from D2-mediated deiodination remains within the cell (1). Thus, this deiodinase provides a mechanism by which thyroid hormone (TH) can be activated in a tissue-specific chronologically programmed fashion, such as during development, or in circumstances where there is a requirement for rapid increase in active $\mathrm{TH}$ in a specific tissue. The effectiveness of this mechanism has been shown in the D2dependent feedback regulation by $\mathrm{T} 4$ of the thyrotropin-releasing hormone and thyroid-stimulating hormone (TSH) secretion by the hypothalamus and pituitary (2). A programmed transient increase in D2 is required for the proper increase in $\mathrm{T} 3$ at a critical time in the embryonic mouse brain (3) to allow normal development of the cochlea $(4,5)$, and a sympathetic nervous system-induced increase in $\mathrm{D} 2$ provides the cellular $\mathrm{T} 3$

Authorship note: Alessandro Marsili and Raffaele Ambrosio contributed equally to this work.

Conflict of interest: The authors have declared that no conflict of interest exists. Citation for this article: J Clin Invest. 2010;120(11):4021-4030. doi:10.1172/JCI43670. to brown adipocytes, which is essential for acute thermogenesis in the cold-exposed rodent or human infant (6). Mice null for the gene encoding D2 (Dio2) exhibit pituitary resistance to the feedback regulation by $\mathrm{T} 4$, with elevated $\mathrm{T} 4$ and $\mathrm{TSH}$, but normal T3 levels in the circulation (7).

Muscle is a major target of hormone action, highly sensitive to $\mathrm{TH}$ concentrations, and expresses D2 $(8,9)$. Functional muscle alterations are common clinical findings in patients with either hyper- or hypothyroidism. A number of genes important for physiological muscle function and its metabolic processes are either positively or negatively regulated by $\mathrm{TH}(10-12)$. Among the genes transcriptionally stimulated by T3 is $M y o D$ (13), the master regulator of the myogenic developmental and regeneration program.

Forkhead box O (FoxO) is a subclass of forkhead box transcription factors that regulates diverse cellular functions, such as differentiation, metabolism, proliferation, and survival (14). Like all forkhead factors, FoxOs share a conserved DNA-binding domain responsible for recognizing consensus forkhead regulatory elements (FREs). Mammalian cells employ multiple FoxO paralogs: FoxO1, FoxO3, FoxO4, and FoxO6. These FoxOs all recognize and bind similar DNA sequences, and some functional redundancy may be present under certain circumstances $(15,16)$. Many signaling pathways converge on FoxO, but inactivation by Akt phosphorylation appears to be a prevalent mechanism in different cellular contexts (17). Although FoxOs have been functionally implicated in muscle differentiation, skeletal muscle-specific genes directly targeted by FoxOs are mostly unknown. FoxO3 binds the MyoD promoter and, in concert with Pax3/7, regulates its cell-specific transcriptional activation in myoblasts (18). 
A
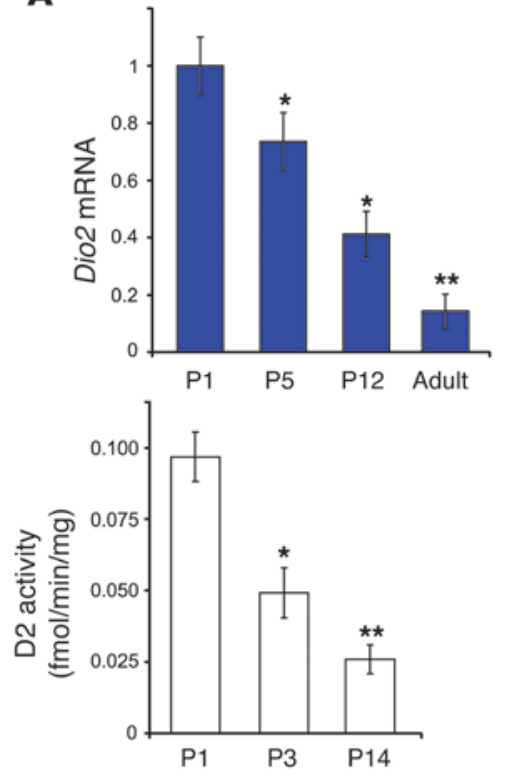

D

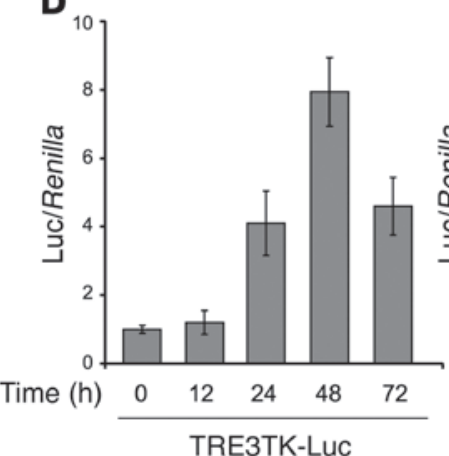

B
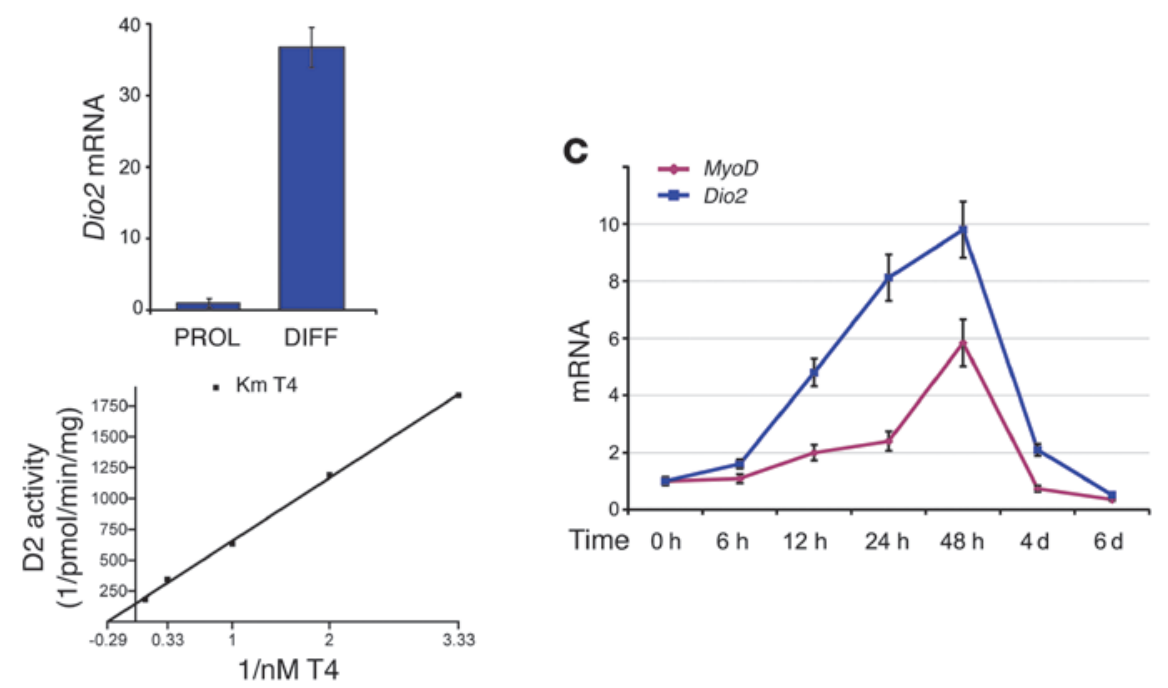

\section{Figure 1}

$\mathrm{D} 2$, expressed in $\mathrm{mpc}$, is induced during differentiation and enhances intracellular thyroid hormone signaling. (A) Dio2 mRNA (top) and activity (bottom) in mouse TA muscles at indicated ages. Data are expressed as mean $\pm \mathrm{SEM}$ of at least 3 independent experiments. ${ }^{\star} P<0.05,{ }^{\star \star} P<0.01$ compared with P1 mice; $n=6$. (B) Mouse primary pp6 cells were isolated from newborn mouse skeletal muscle (see Methods) and cultured in proliferative (PROL) or differentiating (DIFF) conditions for 48 hours before measurement of Dio2 mRNA (top) and activity (bottom). (C) Differentiation was induced in $\mathrm{C} 2 \mathrm{C} 12$ cells, and Dio2 and MyoD mRNA expression was measured by RT-PCR at the indicated times. (D) C2C12 cells (left) or C2C12 cells stably transfected with control (shCTR) or specific D2 shRNA plasmid (shD2) (right) were transiently cotransfected with a T3-responsive reporter (TRE3TK-Luc) and CMV-Renilla plasmid as internal standard, and differentiation was induced for the indicated times. The Luc/Renilla value from mock-transfected plasmid was arbitrarily set as 1. (E) C2C12 cells were transfected with the indicated plasmids and TRE3TK-Luc reporter and MyoD levels measured thereafter. Error bars represent SD.

Because normal TH levels are required for efficient muscle homeostasis, function, and regeneration (19), we hypothesized that D2-mediated $\mathrm{T} 4$ to $\mathrm{T} 3$ conversion might play a significant role in this process. The current studies were undertaken as a step toward further understanding the role of D2 in muscle. Interestingly, we found that Dio2 mRNA and activity are present in muscle stem cells and increase during muscle differentiation. Despite the presence of normal plasma T3 concentrations in D2-null mice, these animals are hypothyroid at the muscle level and show an inadequate $\mathrm{MyoD}$ response to cardiotoxin injury and a marked delay in subsequent muscle regeneration, as indicated by both histological criteria and the pattern of gene expression. The key molecule coordinating the D2-mediated T3 signaling is FoxO3. Thus, a dynamic muscle-specific surge in D2 activity leading to increased T3-dependent transcription is an essential component of normal muscle development and regeneration.

\section{Results}

D2 is highly expressed in muscle progenitor cells. Since normal TH levels are required for efficient muscle development (19), we hypothesized that D2-mediated T4 to T3 conversion might play a significant role in this process. To address this question, we measured D2 in muscle tissues and found low levels of Dio 2 mRNA in normal adult mouse muscle but much higher levels in newborn pups, at a time when satellite cells and myoblast precursors are more prevalent. Dio2 expression decreased over the next 12 days and was even lower in adult muscle (Figure 1A). Consistent with these findings, muscle D2 activity was robust at P1 but fell rapidly over the first few days of life (Figure 1A). In the same tissues, we observed a similar pattern of Pax7 expression (Supplemental Figure 1; supplemental material available online with this article; doi:10.1172/JCI43670DS1), a marker of the satellite cell compartment and myogenic precursor cells (20). 
A
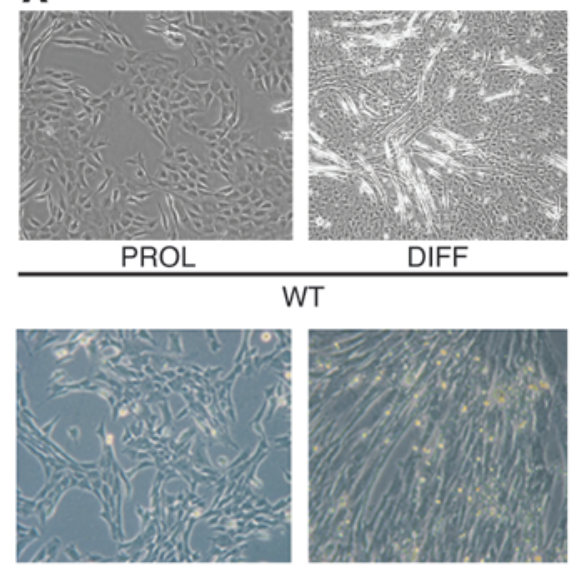

PROL

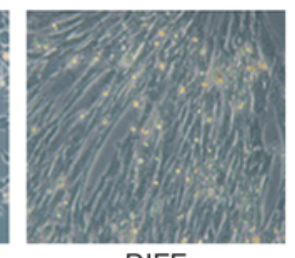

DIFF

shCTR

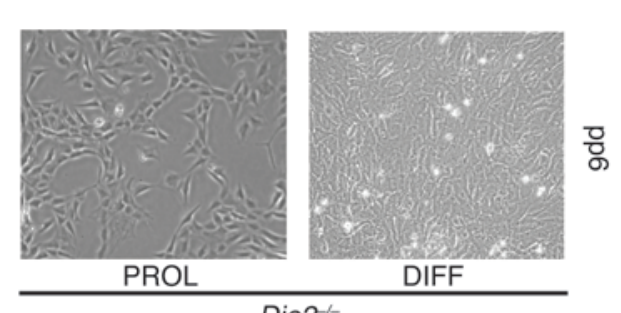

Dio2--

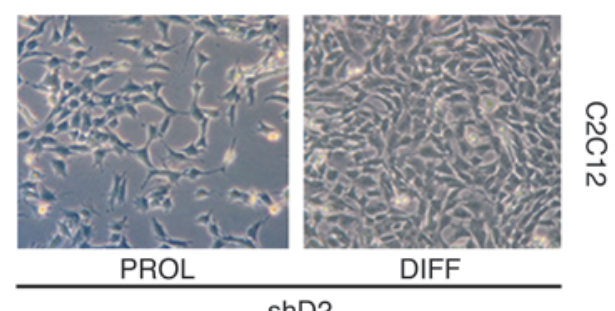

shD2
B

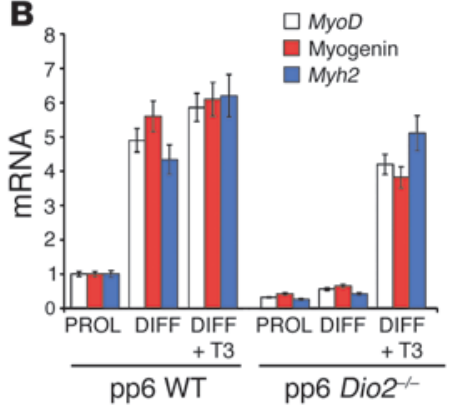

C

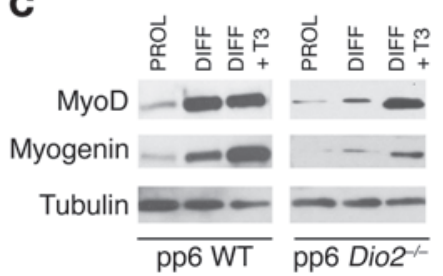

\section{Figure 2}

Blocking D2 impairs myogenic differentiation of mpc. (A) Primary pp6 from wild-type or Dio2 ${ }^{-/-}$mice and C2C12 mock-transfected (shCTR) or shD2 cells were cultured in proliferative or differentiating conditions as indicated. Scale bar: $100 \mu \mathrm{m}$. (B) cDNAs were prepared from pp6 cells from wild-type or Dio2-/- mice and cultured in proliferative and differentiating conditions in the presence of vehicle or $30 \mathrm{nM}$ T3 as indicated. cDNAs were analyzed for MyoD, myogenin, and Myh2 expression by RT-PCR. For each gene, normalized copies of the target gene in proliferating wild-type pp6 cells were set as 1 . Values are mean \pm SEM of 4 independent experiments (C) Western blot analysis of total lysates from pp6 cells cultured as in $\mathbf{B}$. Tubulin levels were measured as loading control.

These observations prompted us to determine whether D2 was expressed in myoblast precursor cells. To this end, an enriched population (pp6) of adult mouse primary muscle precursor cells $(\mathrm{mpc})$ was isolated and cultured under conditions favoring either replication or differentiation (21). Dio2 mRNA expression was detected in proliferating $\mathrm{mpc}$; interestingly, both mRNA expression and activity were strongly increased during differentiation (about $7 \mathrm{fmol} / \mathrm{min} / \mathrm{mg}$ in differentiating precursors) (Figure 1B).

Next, we wished to determine whether the mouse C2C12 myoblasts would be an amenable cell system for the study of D2 expression given their ability to differentiate from myoblasts to myotubes. Dio2 mRNA was also increased in C2C12 myoblasts within 12 hours of the initiation of differentiation and peaked at 48 hours, declining rapidly thereafter (Figure 1C). This surge was completely blocked by actinomycin D (Supplemental Figure 2) and preceded the increase in MyoD (Figure 1C), a T3-responsive master regulator of activated satellite cells (22). Increased intracellular TH signaling paralleled the induction of Dio2 mRNA during differentiation, an effect absent in shD2 cells (Figure 1D), in which D2 expression was constitutively reduced by RNA interference (Supplemental Figure 3), while forced D2 expression caused a robust increase in intracellular T3 and $M y o D$ expression (Figure 1E). Thus, a marked increase in T3-dependent signaling occurs during myoblast differentiation, due to the increased D2-mediated T4 to T3 conversion.

$D 2$ is required for the execution of the myogenic program of $m p c$, and Dio2 $2^{-1-}$ mice showed muscle-specific hypothyroidism. Is D2 essential for the normal differentiation process in myoblasts? We analyzed pp6 cells derived from Dio2-null mice. These cells were impaired in the differentiation process as demonstrated by their morphology (Figure 2A) and the reduced expression of relevant genes including $M y o D$, myogenin, and myosin, heavy polypeptide 2 , skeletal muscle (Myb2) at both the mRNA and protein levels despite the differentiat- ing conditions (Figure 2, B and C). This deficit was rescued by addition of supraphysiological T3 concentrations (Figure 2, B and C), as well as by MyoD overexpression (Supplemental Figure 4), circumventing the requirement for D2.

In parallel, shD2 cells retained a refractile, stellate, fibroblastlike morphology under proliferating conditions and did not differentiate despite appropriate stimuli (Figure 2A and Supplemental Figure 3). Similar effects were obtained in C2C12 cells in which $\mathrm{D} 2$ expression and activity were transiently blocked by RNAi oligonucleotide or rT3 (30 nM) treatment (23), respectively (Supplemental Figure 5). Reverse T3 $\left(3,3^{\prime}, 5^{\prime}-\mathrm{T} 3\right)$ is a naturally occurring inactive iodothyronine and a substrate for D2 enzyme. It is a competitive inhibitor of D2-mediated T4 to T3 conversion and selectively reduces D2 activity by inducing its ubiquitin-mediated inactivation (23). Importantly, differentiation defects induced by $\mathrm{D} 2$ blockade could be rescued not only by $\mathrm{D} 2$ or T3, but also by $\mathrm{T} 4$ when its intracellular conversion to T3 was allowed, i.e., in the presence of active D2 (Supplemental Figure 6).

To gain further insight into the role of D2 in vivo, we analyzed muscles from Dio2-null mice. Firstly, we measured several myogenic markers at different postnatal ages. Interestingly, limb muscles from Dio2-null mice showed differentially expressed levels of several differentiation markers, both early postnatally and in adult life (Figure 3). In particular, expression levels of well-known T3-responsive genes were altered in Dio2-null muscles. The features of Dio2null muscles (i.e., the expression levels of T3-responsive genes such as $M y o D$, troponin 1, troponin 2, and SERCA2) were typical of mildly hypothyroid mice, indicating that, despite the normal plasma T3 concentrations, muscles were hypothyroid in the absence of D2.

In summary, the absence of D2 causes a time-dependent and reversible arrest of the differentiation program due to the failure of intracellular nuclear T3 to reach sufficiently high concentrations to initiate and sustain the differentiation process in vitro and 

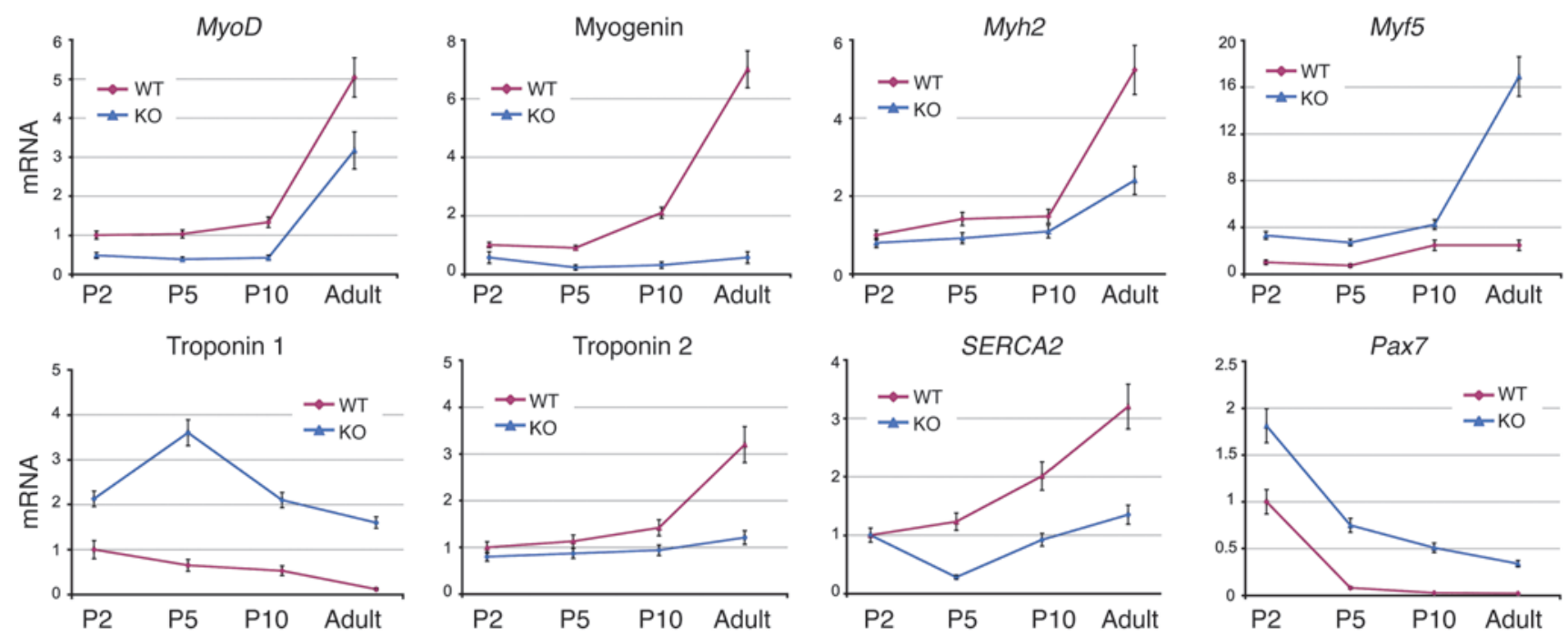

Figure 3

Dio2-null muscles present a phenotype of mild hypothyroidism. mRNA was extracted from TA muscles from wild-type and Dio2 $2^{-/-}$mice $(n=6)$ at different ages, and the indicated gene expressions were measured by RT-PCR. Cyclophilin A was used as internal control. For each gene, normalized copies of the target gene in tibial muscle at P2 were set as 1. Data are expressed as mean \pm SEM of at least 3 independent experiments.

in vivo. The Dio2 ${ }^{-/-}$mice are not able to overcome this T3 deficiency and therefore are hypothyroid at the muscle level both early postnatally and in adult life.

MyoD is a T3-responsive transcription factor that plays an essential role in muscle cell differentiation $(24,25)$. The pp 6 cells from Dio2null mice, or the wild-type cells incubated in the absence of TH failed to differentiate (Figure 2 and Supplemental Figure 4); in contrast, either T3 treatment or MyoD expression rescued their differentiation program (Figure 2B and Supplemental Figure 4), indicating that D2-produced T3 lies upstream of MyoD during differentiation.

$D 2$-generated $\mathrm{T} 3$ is critical in the control of the proliferation of $m p c . \mathrm{T} 3$ often acts as a differentiating agent, controlling the balance between proliferation and differentiation. We have previously shown that proliferation is reduced by $\mathrm{T} 3$ treatment in basal cell carcinomas (26). Using the same rationale, we hypothesized that blocking D2 would lead to increased mpc proliferation. In mpc from Dio2-null versus wild-type mice, we observed an increase in cellular proliferation, as demonstrated by direct measurement of cell numbers, $\left[{ }^{3} \mathrm{H}\right]$ thymidine uptake, and cyclin D1 levels (Figure 4). A similar effect was also observed in pp6 cells and $\mathrm{C} 2 \mathrm{C} 12$ cells growing at different TH concentrations (Figure 4 and data not shown) as well as after D2 blocking (Figure 4), indicating that D2-generated T3 is a critical modulator of cellular proliferation in muscle precursors.

D2 expression in mpc is under FoxO3 control. We then asked how Dio2 is induced during muscle differentiation. To address this question, we evaluated the effects on Dio2 mRNA expression of various transcription factors known to be critical regulators of muscle myogenesis. Interestingly, among several tested muscle transcription factors (Supplemental Figure 7A), a constitutively active FoxO3 (14) significantly induced Dio 2 mRNA in pp6 and C2C12 cells in both proliferating (4-fold) and differentiating (36-fold) conditions (Figure 5A), as well as in 5 different rhabdomyosarcoma cell lines (Supplemental Figure 7B), a solid tumor thought to originate from muscle stem cells (27).

To identify the molecular mechanisms underlying D2 regulation by FoxO3, we investigated whether FoxO3 directly controls the Dio 2 promoter. We found 3 putative FREs within a FoxO3-responsive 1.4-kb Dio2 region (Figure 5B). One of these elements is evolutionarily conserved and efficiently bound FoxO3 as revealed by EMSA (Figure 5B). Mutation of this putative FRE reduces the response of the Dio2 promoter to FoxO3, indicating a functional role for this site (Supplemental Figure 8). Next, we examined the promoter occupancy of FoxO3 on the Dio2 gene. ChIP analysis revealed that FoxO3 was present on the Dio2 promoter overlapping this site (Figure 5C). Interestingly, the occupancy of this site was significantly enhanced following differentiation (Figure 5C), confirming an in vivo correlation between FoxO3 binding and Dio 2 gene transcription. Taken together, these results demonstrate a physical association and a positive transcriptional action of FoxO3 on the Dio2 gene.

Differentiated myocytes showed increased FoxO3 mRNA and activity levels (Supplemental Figure 8B), consistent with FoxO3 as a relevant inducer of $\mathrm{D} 2$ during differentiation. This was also observed in mouse postnatal muscle development, when Foxo3 mRNA levels decreased in parallel with D2 expression (Supplemental Figure 1B). The dependency of D2 expression on FoxO3 was demonstrated by the very low D2 levels in pp 6 cells from $\mathrm{Foxo}^{3^{+-}}$mice (virtually depleted of FoxO3 in heterozygosity; ref. 18) after induction of differentiation or in wild-type pp6 cells expressing a dominantnegative FoxO3 (Figure 5D). Accordingly, Dio2 mRNA in vivo was significantly reduced in muscle from Foxo3-null mice (Figure 5D). In agreement with this finding, Dio2 mRNA was greatly reduced in shFoxO3 C2C12 cells and was appropriately rescued by reexpression of an RNAi-resistant FoxO3 (Figure 5E).

To evaluate whether FoxO3 activity would affect intracellular TH signaling by inducing the D2 enzyme, we measured TRE3TK-Luc in different conditions corresponding to different FoxO3 levels. FoxO3 enhanced intracellular T3 in a dose-dependent fashion (Supplemental Figure 7C), while T3 was consistently reduced in FoxO3-depleted C2C12 cells (Supplemental Figure 9). It has been previously demonstrated that in shFoxO3 cells, the lack of differentiation is associated with impaired $M y o D$ transcription and is partially rescued by MyoD overexpression (18). If D2 action lies between FoxO3 and MyoD expression, then forced expression of D2 - or T3 treatment - in 
A
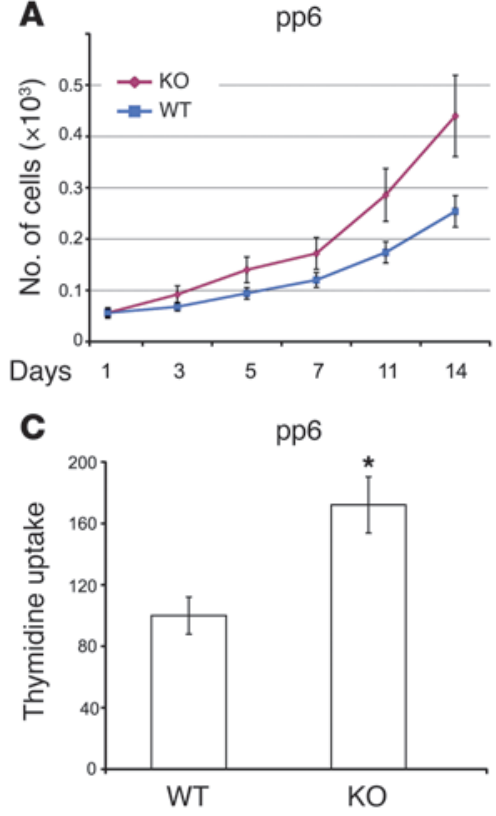

$\mathbf{E}$

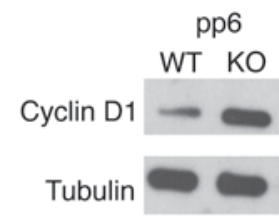

B

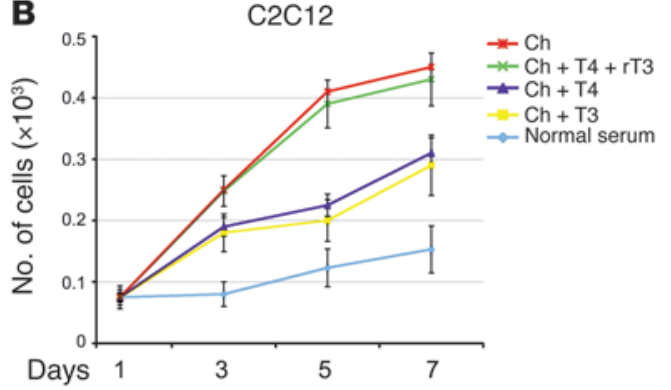

D

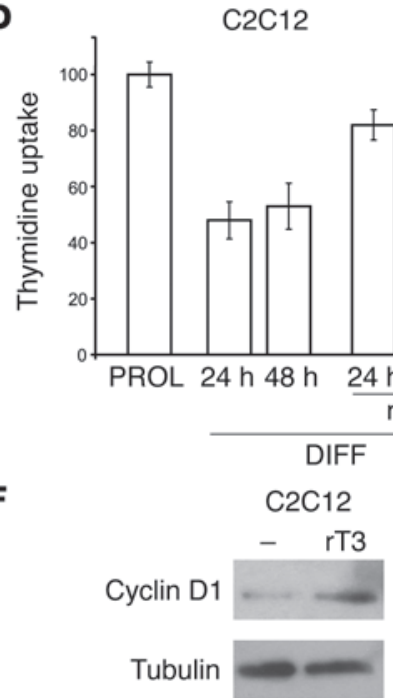

\section{Figure 4}

Blocking D2 or T3 deprivation increases the proliferation rate of primary myoblasts and $\mathrm{C} 2 \mathrm{C} 12$ cells. (A and B) Proliferation curve was performed in pp6 cells from wild-type and Dio2 $2^{-/-}$ mice $(\mathbf{A})$ and $\mathrm{C} 2 \mathrm{C} 12$ cells cultured in normal serum or in charcoal-stripped (Ch) serum supplemented with vehicle or the indicated hormones (B). Error bars represent SD. (C and $\mathbf{D})$ pp6 cells from wild-type or Dio2 $2^{-/-}$mice (C) and C2C12 cells (D) were incubated for 1 hour with [methyl- ${ }^{3} \mathrm{H}$ ] thymidine to a final concentration of $0.05 \mathrm{mCi} / \mathrm{ml}$. $\left[{ }^{3} \mathrm{H}\right]$ Thymidine incorporation in control cells was arbitrarily set as $100 .{ }^{*} P<0.05$ compared with wild-type cells. Data are mean \pm SEM from 3 independent experiments. (E and $\mathbf{F}$ ) Western blot analysis of cyclin D1 levels in pp6 (E) and $\mathrm{C} 2 \mathrm{C} 12$ cells (F). Tubulin was used as loading control.
FoxO3-depleted cells should rescue differentiation defects through expression of MyoD (18). Interestingly, exogenous $\mathrm{T} 3$ was able to rescue MyoD expression and differentiation defects in $\mathrm{Foxo3}^{+/-}$derived pp6 cells as well as in wild-type cells expressing a dominant-negative FoxO3 construct (Figure 5, F and G). Consistent with this finding, the differentiation program induced by Fox 3 was completely abrogated in Dio2-null cells or by blocking D2 (Figure 5, G and H).

These gain-of-function studies taken together with our loss-offunction analysis strongly point to $\mathrm{FoxO} 3$ as a potent activator of D2 expression in mpc. Furthermore, our findings link changes in FoxO3 activity to the modulation of $\mathrm{TH}$ signaling in cells, via its effect of increasing D2 expression.

D2 is induced in muscle regeneration. Since D2 action is essential for muscle differentiation, we asked whether D2 plays a role in vivo in muscle regeneration in adult mice. Notably, following injury or during disease, quiescent satellite cells become activated and proliferate to produce committed mpc, which then repair injured muscle (28). This pattern of adult myogenesis is thought to recapitulate, to a great extent, the pattern of myogenesis during development (29).

First, we examined the expression patterns of D2 following injury induced by the snake venom cardiotoxin (30). Four days after cardiotoxin injury in the tibialis anterior (TA) muscle $(28,29)$, expression levels of Dio2 mRNA increased significantly and reached a peak at day 11 (Figure 6A). Thereafter, Dio2 mRNA declined, reaching normal levels by day 21 (Figure 6A and data not shown). In a similar experiment, D2 activity showed a consistent pattern (Figure 6B). Interestingly, no changes in serum $\mathrm{T} 3$ or $\mathrm{T} 4$ concentrations were observed at any time during the cardiotoxin experiment (Figure 6C and Supplemental Figure 10), indicating that the D2-induced
$\mathrm{T} 3$ production at the injury site affects only the muscle compartment. By day 15 after injury, after the surge of D2, regeneration was nearly completed, with the myonuclei localized at the periphery of myofibers (Figure 7, A and D). Overall, these data show that D2 is induced in vivo during regeneration of adult skeletal muscle, causing tissue-specific enhancement of TH signaling in muscle cells without perturbing circulating TH levels.

Defective muscle regeneration in Dio2 ${ }^{-/-}$mice following cardiotoxininduced muscle injury. Next, we speculated that D2 might play a critical role in the regulation of muscle regeneration. To test this hypothesis, we compared the regeneration potential of Dio2-null mice versus wild-type animals using the cardiotoxin-induced muscle injury paradigm. Cardiotoxin injection into the TA muscles caused considerable damage, triggering a robust regenerative response similar to that in wild-type animals. However, regeneration repair was significantly delayed in Dio2-null compared with wild-type mice. Notably, no obvious differences were observed at early time points after injury (i.e., day 4), when the extent of muscle fiber necrosis and the number of nonmyogenic cells within the damaged site were similar in the two groups of animals (Figure 7D). In contrast, examination of H\&E-stained transverse sections of Dio2 ${ }^{-/-}$mice at a later time in the regeneration experiment revealed a striking difference in the D2-null versus wild-type animals, particularly evident at day 15 after injury (Figure 7D), soon after the surge of D2 occurs in wild-type mice. Indeed, while regeneration was almost complete at this time in wild-type muscle, with most of the myonuclei localized at the periphery of myofibers, Dio2-null muscles still showed a greater number of newly formed centrally nucleated myofibers, indicating that regeneration was delayed. To 
A
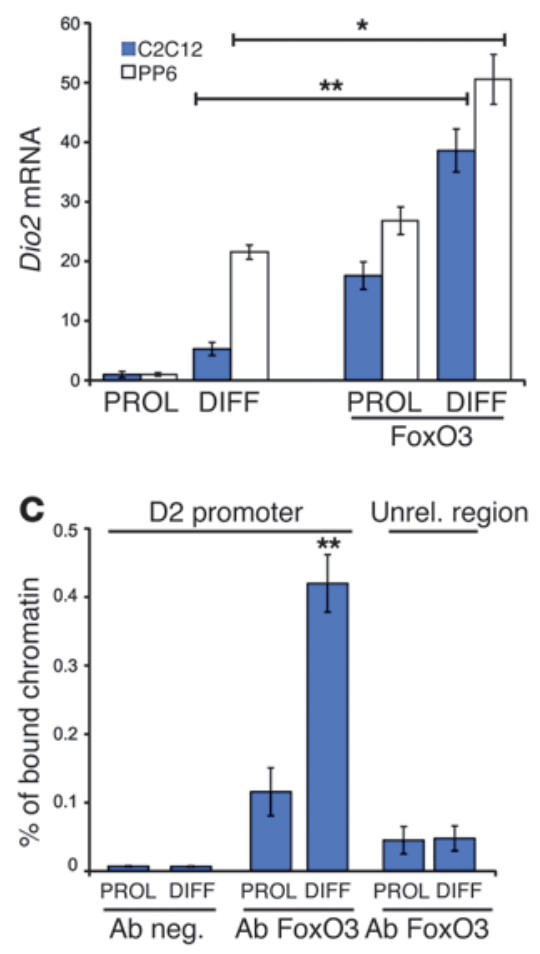

$\mathbf{F}$

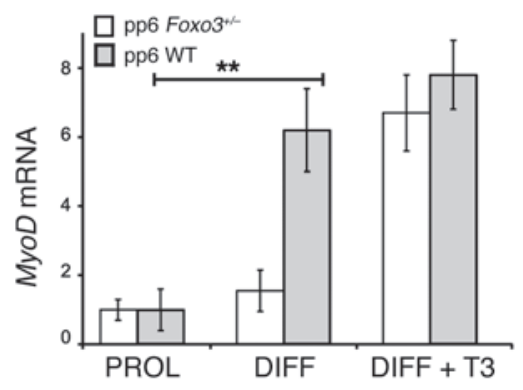

B $\mathrm{FoxO} 3 \mathrm{WT}+++\ldots$ FoxO3 C.A. - - + + + FoxO3 D.N. $-\bar{S} \bar{U}-\bar{S} \bar{U}+$
Comp.

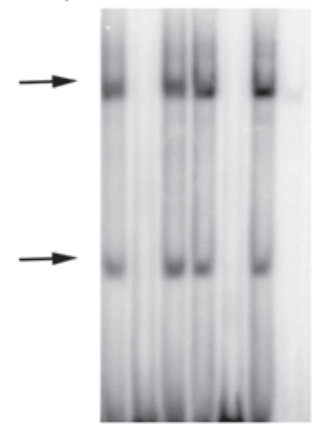

D
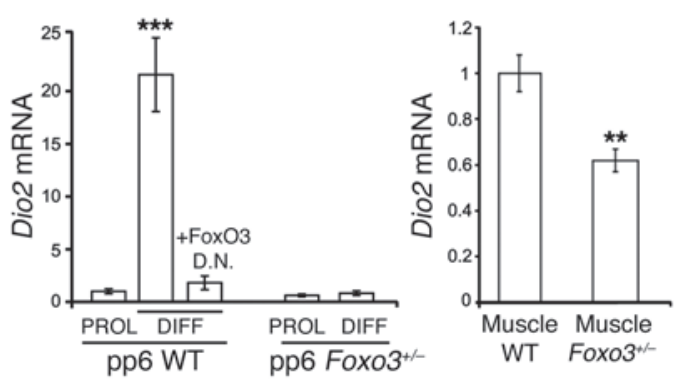

G

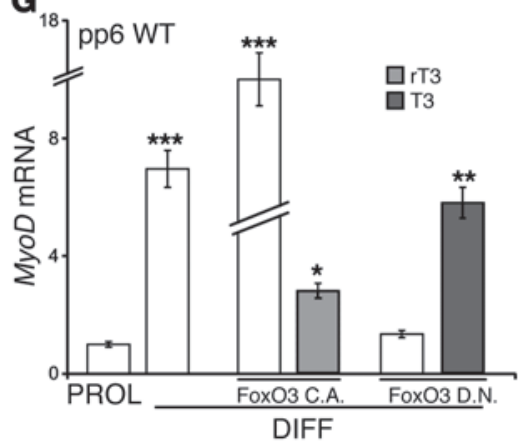

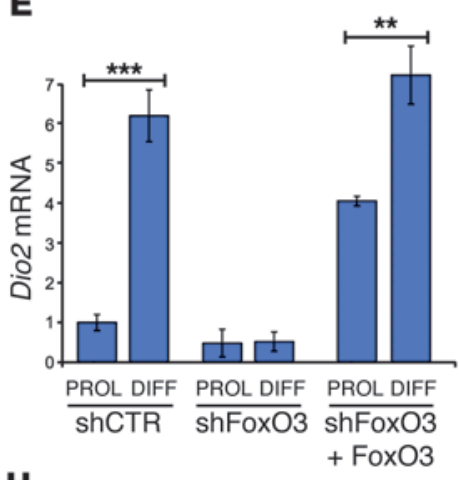

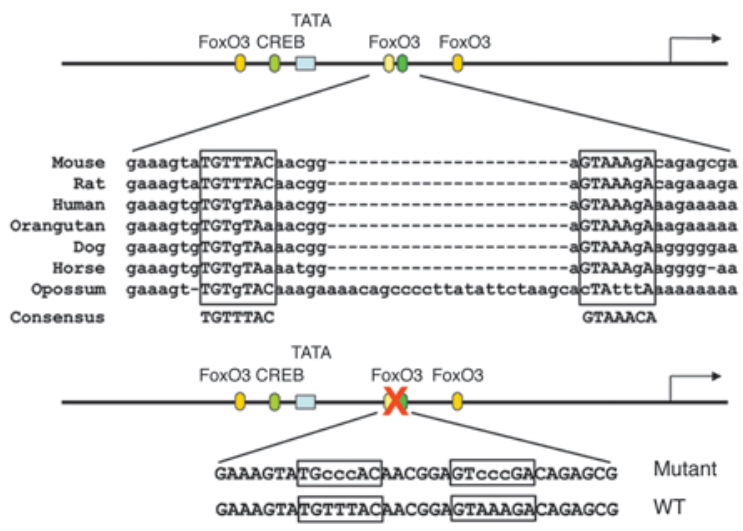

E

H

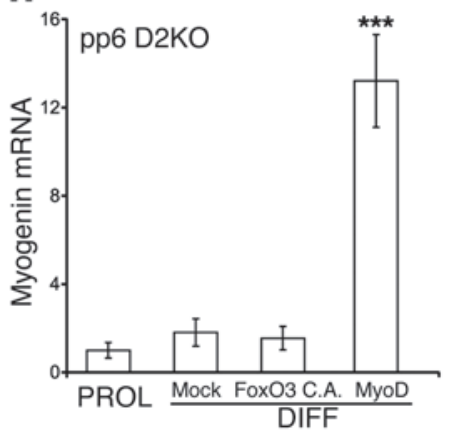

Figure 5

D2 expression in myoblasts is under direct FoxO3 control. (A) $\mathrm{C} 2 \mathrm{C} 12$ or wild-type pp6 cells were transiently transfected with a FoxO3 or empty vector as indicated, and Dio2 mRNA measured 48 hours later by RT-PCR. (B) Left: Nuclear extracts from transfected cells with (+) or without (-) FoxO3 plasmid were analyzed by EMSA as indicated. Right: Schematic representation of mouse Dio2 proximal promoter region. Relevant binding sites and their mutant version are shown schematically. $\mathrm{FoxO} 3$ C.A, FoxO3 constitutively active; Comp., oligonucleotides used for competition (S, self oligo; $\mathrm{U}$, unrelated oligo). (C) ChIP analysis of the interaction between FoxO3 and the mouse Dio2 promoter. Chromatin extracted from $\mathrm{C} 2 \mathrm{C} 12$ cells was immunoprecipitated using the indicated antibodies. Unrel., unrelated genomic region. (D) Left: Dio2 mRNA in pp6 cells from wild-type and Foxo3 ${ }^{+-}$ mice were cultured in proliferative and differentiating conditions and transfected with empty vector or a FoxO3 dominant-negative (FoxO D.N.) expression plasmid. Right: Dio2 mRNA in TA muscles from wild-type and Fox03+- mice. (E) Dio2 mRNA levels were measured by RT-PCR in shCTR or shFoxO3 cells. shFoxO3 cells were transfected with an RNAi-resistant FoxO3 plasmid as indicated. (F) pp6 cells from wild-type and Foxo3 $3^{+/}$- mice were cultured in proliferative and differentiating conditions and treated with vehicle or $30 \mathrm{nM} \mathrm{T3}$. MyoD mRNA was measured by RT-PCR. (G) MyoD mRNA levels in pp6 wild-type cells transfected with empty vector or FoxO C.A. or FoxO D.N. vector and treated with vehicle, T3, or rT3 as indicated. (H) Myogenin mRNA levels in pp6 from Dio2-- mice cultured in proliferative and differentiating conditions and transfected with empty vector, FoxO3 C.A., or MyoD expression vectors. Values are mean \pm SEM of at least 3 independent experiments. ${ }^{*} P<0.05,{ }^{* *} P<0.01,{ }^{* * *} P<0.001$.

obtain a quantitative assessment of regeneration in the two groups, we measured - using computer-assisted software in an operatorblinded approach (31) - the percentage of centrally localized nuclei within the muscle fiber versus the total nuclei (Figure 7A). At day 11 after injection, the number of central nuclei fibers was significantly lower in wild-type versus Dio2-null animals, and this difference was even more pronounced at day 15 , when, as opposed to an almost completed regeneration pattern in wild-type animals, more than $60 \%$ of the fibers in the Dio2-null group contained central nuclei (Figure 7, A-D). These results indicated that while in control mice the regeneration of injured muscle was completed at day 15 , in Dio2 ${ }^{--}$animals this stage of recovery was significantly delayed. 

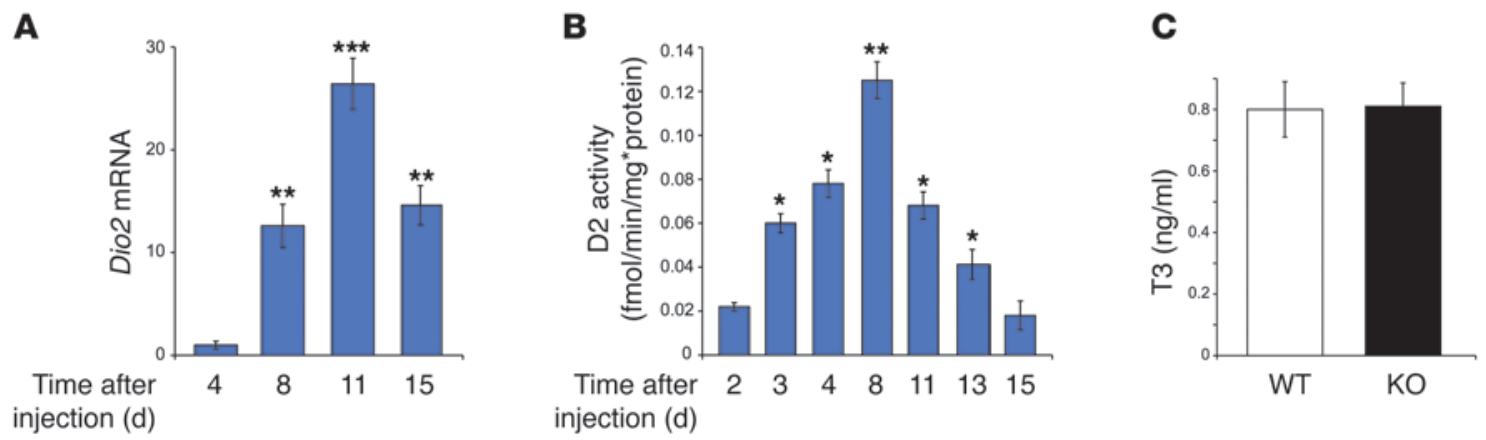

\section{Figure 6}

D2 is induced in muscle regeneration. (A) Dio2 mRNA was measured by RT-PCR during muscle differentiation in wild-type mice. Regeneration was induced by cardiotoxin injection (see Methods) into the TA muscle. ${ }^{* *} P<0.01,{ }^{* * *} P<0.001$ compared with Dio2 mRNA at 4 days after injection; $n=5$. (B) D2 enzymatic activity was measured from total lysates of TA muscles from wild-type mice in which regeneration was induced as in $\mathbf{A}(n=5)$. ${ }^{*} P<0.05, P<0.01$, compared with D2 activity at 2 days after injection; $n=5$. (C) The average of plasma T3 levels in wild-type and D2-null mice during the regeneration experiment. Values are mean \pm SEM.

In agreement with the enhanced proliferation rate of D2-deficient myoblasts (Figure 4), the number of nuclei in regenerating tissues of Dio2-null mice was nearly twice that of the wild-type animals (Figure 7B). Notably, BrdU-positive nuclei were significantly increased (Figure $7 \mathrm{C}$ and Supplemental Figure 11), indicating that the overall myoblast proliferation rate was higher in vivo in the D2-null environment than in controls. Furthermore, in agreement with the enhanced proliferation of mpc, increased Pax7 mRNA levels and increased $\mathrm{Pax} 7^{+}$cells were present in Dio2-null muscles (Figure 3 and Supplemental Figure 12).

To identify the molecular defects arising from the absence of D2 during muscle regeneration, we measured the expression levels of muscle differentiation markers on different days after cardiotoxin injection. Interestingly, MyoD was dramatically reduced in Dio2 $2^{-/-}$ mice at both mRNA and protein levels, an effect particularly evident at day 15 following injury (Figure 7E and Supplemental Figure 13). Furthermore, downstream MyoD effectors, such as myogenin, MHC, as well as the regeneration marker neonatal MHC (32), were also dramatically reduced in the absence of $\mathrm{D} 2$ at both mRNA and protein levels (Figure 7E and Supplemental Figure 13), which indicates that terminal differentiation is impaired by the absence of D2.

These injury and regeneration experiments revealed a distinct delay in skeletal muscle regeneration in Dio2 $2^{-/-}$mice compared with wild-type animals. This delay was caused by the defective differentiation in the absence of active D2 in the face of an enhanced cellular proliferation of myoblast precursor cells. In summary, our data indicate that the normal plasma T3 concentration of the Dio2 $2^{-/}$mouse was insufficient to supply the requirements of the muscle for normal myogenesis and regeneration.

\section{Discussion}

Although an essential role of TH in muscle function is well recognized, a requirement for local control of thyroid signaling during muscle differentiation and repair has not been previously identified. Our results indicate that a time-dependent and cell-autonomous amplification of TH signaling in myoblasts is critical for proper muscle differentiation and for muscle repair. This amplification is obtained by a rapid induction of D2 in satellite cells (Figure 1, A-C). The increase in D2-mediated T4 monodeiodination increases nuclear T3 receptor saturation, as reflected by the marked induction in expression of the T3-dependent luciferase reporter (Figure 1D) and expression of T3-dependent genes
(Figure 2, B and C). Blocking D2 with reverse T3 or genetic D2 depletion prevents the increase in intracellular T3 (Figure 1D) and blocks myotube formation, as well as inhibiting the induction of $\mathrm{MyoD}$, myogenin, and MHC, which normally occurs during the differentiation process (Figure 2). The increase in $\mathrm{T} 3$ requires the $\mathrm{D} 2$ substrate T4, which is provided by FBS in the medium. The requirement for D2 or for T4 can be obviated by addition of supraphysiological concentrations of T3 (Figure 2, B and C). In addition to inducing MyoD and causing formation of myotubes, the increase in intracellular T3 reduces cell proliferation (Figure 4).

The reason why D2 is critical to the process of differentiation is that even in vitro, whatever intracellular T3 is provided by the FBS in the medium is insufficient to induce terminal muscle differentiation. The in vivo studies also mirror this requirement for a high intracellular T3 in that a normal concentration of circulating T3 in the Dio2-null mice is not sufficient to support normal myogenesis and muscle repair after cardiotoxin injury (Figure 4). At this time, it is not clear which T3-dependent gene(s) require this high degree of $\mathrm{T} 3$ receptor saturation for appropriate induction, but $M y o D$, given its central role in the process of myoblast differentiation and its $\mathrm{T} 3$ responsiveness, is a very likely candidate.

A number of agents have been shown to stimulate Dio2 gene transcription, including cyclic AMP, glucocorticoids, and the NF-кB pathway (33). In the opposite direction, previous studies by Dentice et al. have indicated that the Hedgehog proteins, by inducing a specific E3 ubiquitin ligase, accelerate D2 degradation (23). We show here that the Dio2 gene in muscle cells is under the direct control of FoxO3 (Figure 5, A and B). FoxO family members play a direct role in regulating myogenesis and, by cooperating with the PAX3/7 proteins, FoxO3 activates $M y o D$ transcription in myoblasts (18), likely, based on the present results, in combination with T3. In light of our results, amplification of T3 signaling is required for the execution of the FoxO3 program in myogenesis.

Interestingly, a recent study demonstrated that Foxo3-null mice had impaired myogenesis and muscle regeneration, partially rescued in vitro by MyoD replacement. This deficit occurs also in the heterozygous condition (18), indicating that the loss of a single Foxo3 allele is sufficient to induce a defect in myogenesis. Accordingly, in satellite cells and hind muscles from Foxo3 $3^{+/-}$mice, Dio2 expression was significantly reduced (Figure 5D), supporting the concept that Dio2 transcription is under FoxO3 control. Dio2 as well 
A

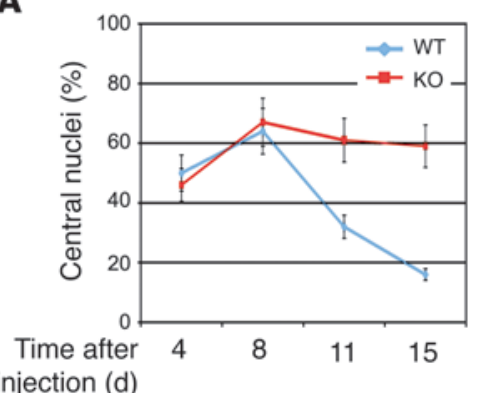

B

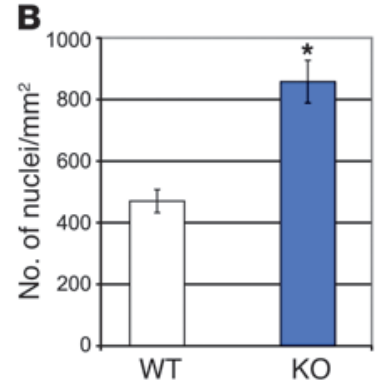

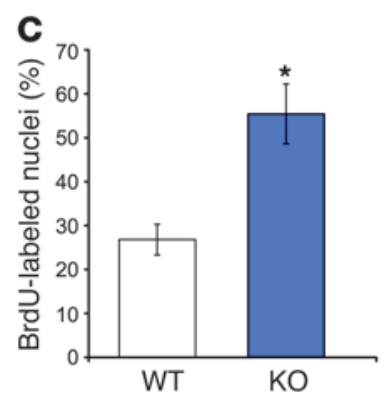

D15 DAPI
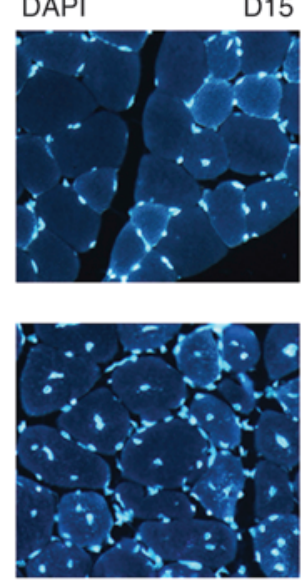

E

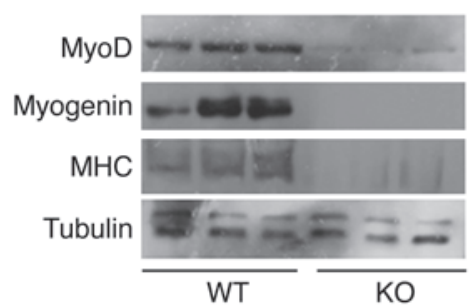

$\mathbf{F}$

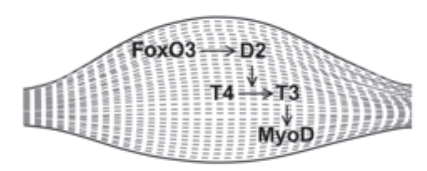

\section{Figure 7}

Defective muscle regeneration in Dio2-/- mice. (A) The percentage of centrally located nuclei was evaluated in H\&E-stained TA muscle sections from D2KO and wild-type mice at 4-15 days after cardiotoxin (CTX) injection. (B) Number of nuclei was evaluated in H\&E-stained TA muscle sections from Dio2 $^{-l-}$ and wild-type mice at 15 days after CTX injection. ${ }^{*} P<0.05$ compared with wild-type mice; $n=20$. (C) Percentage of BrdU-labeled nuclei in TA muscle sections from Dio2 ${ }^{-/-}$and wild-type mice at 15 days after CTX injection. ${ }^{*} P<0.05$ compared with wild-type mice; $n=50$ slides. Data are shown as average \pm SD. (D) H\&E-stained and DAPI-stained TA muscle sections (original magnification, $\times 40$ ) from Dio2--- and wild-type mice at 4 and 15 days after CTX injection. (E) Western blot analysis of total lysates from tibial muscles from 3 different mice at 15 days after CTX injection from the same experiment as in A. Tubulin was used as loading control. (F) The FoxO3/D2 axis promotes muscle differentiation in muscle cells by inducing MyoD expression.

as relevant T3-responsive genes were similarly reduced in adenoCre-infected satellite cells from Foxo $3^{f / f l}$ mice (data not shown). Finally, FoxO3 levels in postnatal muscles were highest at $\mathrm{P} 1$, a time when Dio2 mRNA and activity were also elevated (Figure 1A).

Together, these data are consistent with the concept that FoxO3 induces D2, which in turn allows proper MyoD transcription and differentiation (Figure 7F). Supporting this notion, D2 is able to compensate for FoxO3 deficiency in satellite cells, indicating that $\mathrm{D} 2$ acts downstream of the FoxO3 protein but upstream of MyoD in the differentiating program (Figure 4).

Independent support for a FoxO3/D2 relationship is found in studies of rhabdomyosarcoma cell lines in which Dio2 mRNA was markedly induced by FoxO3 overexpression (Supplemental Figure 7 ). We used these cells as a paradigm of a cellular environment corresponding to abortive myogenesis to assess the potential of FoxO3 as a D2 inducer. In these tumors, an oncoprotein is frequently present that acquires the potent transactivation domain of the FoxO gene and the Pax DNA-binding domain by which it binds to the Pax target genes (34). In this context, the transcription of Pax-dependent genes is enhanced, and the normal FoxO3 targets are reduced. In a cell with functionally reduced FoxO3 activity, the restoration of FoxO3 activity would be predicted to greatly enhance D2 expres- sion. The finding that $\mathrm{D} 2$ is markedly responsive to FoxO3 in RMS cells strongly supports this notion, in agreement with the direct correlation of D2 and FoxO3 levels in muscle precursors (Figure 5).

FoxO3 is induced during muscle atrophy (35), and this observation is consistent with the presence of elevated D2 in the skeletal muscle of chronically ill rabbits (36). Furthermore, dexamethasone induces FoxO3 in C2C12 cells (37), perhaps explaining how corticosteroids can induce D2 expression. Further studies will be necessary to dissect the putative role of D2 in the context of atrophy.

The Dio2 $2^{-/-}$mouse exhibits signs of TH deficiency in tissues where D2 is known to play an important role. While we did not observe any compensatory effect of other deiodinases, we clearly demonstrated that the Dio2 $2^{-/-}$mice exhibit a hypothyroid phenotype at a muscle level, which is a delayed and incomplete differentiation. Hind muscles from Dio2 $2^{-/-}$mice showed signs of hypothyroidism, i.e., a gene expression pattern consistent with type I muscle fibers - since T3 promotes the development of type II fibers - as well as showing lower specific expression of genes known to be T3 responsive (10), such as $M y o D$, myogenin, Myb2, SERCA2, and troponin 2 (Figure 3). Accordingly, troponin 1, which is downregulated by T3 and upregulated in type I fibers, was increased in Dio2 $2^{-/-}$hind muscles 
(Figure 3). This deficit, particularly evident during active myogenesis in early postnatal life or cardiotoxin-induced regeneration, persists in adult life despite normal plasma T3 levels and the apparent normal gross appearance of the Dio $2^{-/-}$muscles. In summary, this study indicates that physiological concentrations of T3 in the plasma are not sufficient to guarantee normal myogenesis in postnatal life, during regeneration, and in adulthood. The Dio2 $2^{-/-}$mice are not able to overcome this T3 deficiency and therefore are hypothyroid at the muscle level both early postnatally and in adult life.

Several reports demonstrated the important effects of altered $\mathrm{TH}$ status on muscle regeneration $(19,38)$. In $m d x$ mice, hyperthyroidism causes a more severe dystrophic phenotype and greater segmental damage in the TA than in control untreated $m d x$ littermates. Systemic hypothyroidism prolongs and increases the phase of replication by $m d x$ muscle precursors and delays fusion into myotubes in regeneration (39). The defects we observed in D2-null muscles during the regeneration process more or less phenocopy both MyoD-null and the hypothyroid mice: in both, myogenic stem cells are increased in number but impaired in their differentiation. The increased satellite cell proliferation and number of Pax $7^{+}$cells (Figure 4 and Supplemental Figure 12) as well as the number of nuclei and the amount of BrdU incorporation during regeneration (Figure 7, B and C) support this concept in vitro and in vivo, respectively.

Why should D2 inhibition represent an advantage for cell proliferation? In many cell contexts, T3 is a differentiating agent, and in this sense it is associated with reduced proliferation. At a nuclear level, the liganded TH receptor acts in many proliferating cells as a tumor suppressor (40). Recent studies demonstrated that freshly isolated satellite cells contribute remarkably to myofiber regeneration after transplantation $(41,42)$. These cells expand extensively and regenerate new myofibers, which is advantageous for injured or dystrophic muscles. In the absence of MyoD, muscle stem cells survive longer and more effectively when transplanted in injured muscle (43). The observation that we transiently downmodulate MyoD by reversibly blocking D2 in myoblast precursors could have several clinical implications for patients with muscle disease. For example, myogenic precursor cells could be kept in low T3 conditions when increased proliferation and cell expansion are desired. Later, the situation could be reversed, by removing the blocking agent or by supplying T3, thus promoting myotube formation and terminal differentiation. This could significantly improve the success of myoblast transplantation protocols in which differentiation limits the degree of mpc proliferation (44). It is important to note that in different tissues, the biological activity of TH is influenced by the activity of $\mathrm{D} 2$ but also, in defined circumstances, by the rate of $\mathrm{T} 4$ and $\mathrm{T} 3$ degradation by the type 3 deiodinase (D3). This occurs especially during development, during liver and nerve regeneration, as well as in circumstances associated with enhanced cellular proliferation, as is the case for inflammatory cells during inflammation or in different tumoral cells $(26,45-47)$. Assessing the role of D3 in developing myoblasts and in the inflammatory cells sustaining muscle regeneration is the object of current studies.

Many tissues require D2 action to perform specific functions. Examples include the pituitary controlling thyrotropin secretion (2), gonadal responses in birds (48), brown adipose tissue thermogenesis (6), and, as shown here, normal skeletal muscle myogenesis and regeneration. This elegant mechanism controlling intracellular $\mathrm{T} 3$ production throughout the vertebrate kingdom is highly advantageous for meeting time-specific local requirements such as the response to injury in muscle - without perturbing plasma TH concentrations. The regulation of D2 by morphogens (23) or, as shown here, by FoxO3 provides potent mechanisms whereby changes in intracellular TH concentrations can be tightly coordinated, allowing cell-autonomous differentiation or proliferation, without affecting the TH supply to other tissues.

\section{Methods}

Cell cultures, transfections, and reagents. Primary muscle cultures (pp6) were isolated as described previously (21) from the indicated mouse lines. C2C12 cells were obtained from ATCC. When cells were $60 \%-70 \%$ confluent, they were induced to differentiate in DMEM with $2 \%$ horse serum (HS), insulin, and transferrin (differentiation medium). RMS cells were provided by P.L. Puri (Istituto Dulbecco Telethon, IRCCS Santa Lucia Foundation and European Brain Research Institute, Rome, Italy). In some experiments, endogenous $\mathrm{T} 3$ and $\mathrm{T} 4$ were removed from the FBS by charcoal absorption (Ch) (49). Anti-MyoD (sc-304), myogenin (sc-12732), tubulin (sc-8035), and anti-FoxO3 antibodies were purchased from Santa Cruz Biotechnology Inc. Polyclonal anti-MHC antibody (MF-20a) was from Developmental Studies Hybridoma Bank.

Plasmids and expression constructs. The luciferase reporter plasmid TRE3TKLuc and the wild-type D2 plasmid are reported elsewhere (50). To knock down D2 in transient transfection experiments, 25-bp Stealth siRNA was purchased from Invitrogen. FoxO3 plasmid was provided by M. Sandri (Department of Biomedical Sciences, University of Padua, Padua, Italy); p6xDBE-Luc was provided by S. Goruppi (Molecular Cardiology Research Institute, Tufts University School of Medicine, Boston, Massachusetts, USA); and Pax7, MyoD, and MEF2a were provided by S. Brunelli (Division of Regenerative Medicine, San Raffaele Scientific Institute, Milan, Italy).

D2 deiodination assays. Muscle tissue was homogenized on ice in phosphate buffer containing $0.25 \mathrm{M}$ sucrose, $1 \mathrm{~mm}$ EDTA, and $10 \mathrm{mM}$ DTT and complete protease inhibitor cocktail from Roche. Reactions were incubated at $37^{\circ} \mathrm{C}$ for 4 hours in $0.1 \mathrm{ml}$ PE buffer with $1 \mathrm{nM}$ or $500 \mathrm{nM} \mathrm{T} 4$ (blank), $20 \mathrm{mM}$ DTT, $1 \mathrm{mM}$ propylthiouracil, with the addition of approximately $2 \times 10^{5} \mathrm{cpm}\left[3^{\prime}-5^{\prime}-125 \mathrm{I}\right] \mathrm{T} 4(11)$. Blank values were subtracted before calculation of deiodinase activities.

Immunofluorescence and immunohistochemistry. For immunofluorescence staining, cells were fixed with $4 \%$ formaldehyde and permeabilized in $0.1 \%$ Triton X-100, then blocked with $0.5 \%$ goat serum and incubated with primary antibody. Alexa Fluor 595-conjugated secondary antibody was used. The cell DNA was stained with 300 nM DAPI (Molecular Probes, Invitrogen). Muscle from Dio2 $2^{-/-}$and wild-type mice was fixed in $4 \% \mathrm{PFA}$, and serial sections were collected.

ChIP. C2C12 cells were fixed with $1 \%$ formaldehyde and subjected to ChIP assay as previously described (23) using a FoxO3, or a preimmune purified IgG as a negative control.

Muscle regeneration studies. Cardiotoxin injection was performed as described previously (51). Briefly, $15 \mu \mathrm{l}$ of $10 \mu \mathrm{M}$ cardiotoxin (Naja nigricollis, Calbiochem) was injected into the right TA muscles of anesthetized 12-week-old C57BL/6 males (The Jackson Laboratory) or age- and sexmatched Dio2-null mice (52). The corresponding left TA muscles were not injected and used as controls. For assessment of BrdU incorporation, mice were injected intraperitoneally with $1 \mathrm{ml} / 100 \mathrm{~g}$ body weight of BrdU (Zymed, Invitrogen) 24 hours before harvesting the muscles, according to the manufacturer's protocol. All animal experimental protocols were approved by the Animal Research Committee of Harvard Medical School.

Statistics. Differences between samples were assessed by Student's 2-tailed $t$ test for independent samples. $P$ values less than 0.05 were considered significant. Relative mRNA levels (in which the first sample was arbitrarily 
set as 1) are reported as results of real-time PCR in which expression of cyclophilin A was used as a housekeeping gene.

\section{Acknowledgments}

We are grateful to C. Cepko, A. Wagers, and D.D. Moore for their critical reading of the manuscript and to J. Harney and M. Mulcahey for technical support. This work was supported by grants from the Associazione Italiana per la Ricerca sul Cancro (AIRC) and Ministero dell'Istruzione, dell'Università e della Ricerca (MIUR) to D. Salvatore; an MFAG grant from the AIRC to M. Dentice; AIRC and Telethon grant GGP08120 to G. Minchiotti; and NIH grant DK044128 to P.R. Larsen.

Received for publication May 11, 2010, and accepted in revised form August 18, 2010.

Address correspondence to: Domenico Salvatore, Department of Molecular and Clinical Endocrinology and Oncology, University of Naples “Federico II,” Via S. Pansini 5, 80131 Naples, Italy. Phone: 39.081.7463780; Fax: 39.081.7463668; E-mail: domsalva@unina.it.
1. Bianco AC, Salvatore D, Gereben B, Berry MJ, Larsen PR. Biochemistry, cellular and molecular biology, and physiological roles of the iodothyronine selenodeiodinases. Endocr Rev. 2002;23(1):38-89.

2. Silva JE, Larsen PR. Pituitary nuclear 3,5,3'-triiodothyronine and thyrotropin secretion: an explanation for the effect of thyroxine. Science. 1977;198(4317):617-620.

3. Galton VA, et al. Thyroid hormone homeostasis and action in the type 2 deiodinase-deficient rodent brain during development. Endocrinology. 2007;148(7):3080-3088.

4. Campos-Barros A, Amma LL, Faris JS, Shailam R, Kelley MW, Forrest D. Type 2 iodothyronine deiodinase expression in the cochlea before the onset of hearing. Proc Natl Acad Sci U S A. 2000;97(3):1287-1292.

5 . $\mathrm{Ng} \mathrm{L}$, et al. Hearing loss and retarded cochlear development in mice lacking type 2 iodothyronine deiodinase. Proc Natl Acad Sci US A. 2004;101(10):3474-3479.

6. Silva JE, Larsen PR. Adrenergic activation of triiodothyronine production in brown adipose tissue. Nature. 1983;305(5936):712-713.

7. Schneider MJ, Fiering SN, Pallud SE, Parlow AF, St Germain DL, Galton VA. Targeted disruption of the type 2 selenodeiodinase gene (DIO2) results in a phenotype of pituitary resistance to T4. Mol Endocrinol. 2001;15(12):2137-2148.

8. Salvatore D, Bartha T, Harney JW, Larsen PR. Molecular biological and biochemical characterization of the human type 2 selenodeiodinase. Endocrinology. 1996;137(8):3308-3315.

9. Grozovsky R, et al. Type 2 deiodinase expression is induced by peroxisomal proliferator-activated receptor-gamma agonists in skeletal myocytes. Endocrinology. 2009;150(4):1976-1983.

10. Simonides WS, van Hardeveld C. Thyroid hormone as a determinant of metabolic and contractile phenotype of skeletal muscle. Thyroid. 2008;18(2):205-216.

11. Heemstra KA, et al. Type 2 iodothyronine deiodinase in skeletal muscle: effects of hypothyroidism and fasting. $J$ Clin Endocrinol Metab. 2009;94(6):2144-2150.

12. Visser WE, et al. Physiological thyroid hormone levels regulate numerous skeletal muscle transcripts. J Clin Endocrinol Metab. 2009;94(9):3487-3496.

13. Muscat GE, Downes M, Dowhan DH. Regulation of vertebrate muscle differentiation by thyroid hormone: the role of the myoD gene family. Bioessays. 1995;17(3):211-218.

14. Accili D, Arden KC. FoxOs at the crossroads of cellular metabolism, differentiation, and transformation. Cell. 2004;117(4):421-426.

15. Burgering BM. A brief introduction to FOXOlogy. Oncogene. 2008;27(16):2258-2262.

16. Maiese K, Chong ZZ, Shang YC. OutFOXOing disease and disability: the therapeutic potential of targeting FoxO proteins. Trends Mol Med. 2008;14(5):219-227.

17. Salih DA, Brunet A. FoxO transcription factors in the maintenance of cellular homeostasis during aging. Curr Opin Cell Biol. 2008;20(2):126-136.

18. Hu P, Geles KG, Paik JH, DePinho RA, Tjian R. Codependent activators direct myoblast-specific MyoD transcription. Dev Cell. 2008;15(4):534-546.
19. McIntosh LM, Pernitsky AN, Anderson JE. The effects of altered metabolism (hypothyroidism) on muscle repair in the $\mathrm{mdx}$ dystrophic mouse. Muscle Nerve. 1994;17(4):444-453.

20. Oustanina S, Hause G, Braun T. Pax7 directs postnatal renewal and propagation of myogenic satellite cells but not their specification. EMBO J 2004;23(16):3430-3439.

21. Qu Z, Balkir L, van Deutekom JC, Robbins PD, Pruchnic R, Huard J. Development of approaches to improve cell survival in myoblast transfer therapy. J Cell Biol. 1998;142(5):1257-1267.

22. Muscat GE, Mynett-Johnson L, Dowhan D, Downes $M$, Griggs R. Activation of myoD gene transcription by $3,5,3^{\prime}$-triiodo-L-thyronine: a direct role for the thyroid hormone and retinoid $\mathrm{X}$ receptors. Nucleic Acids Res. 1994;22(4):583-591.

23. Dentice $M$, et al. The Hedgehog-inducible ubiquitin ligase subunit WSB-1 modulates thyroid hormone activation and PTHrP secretion in the developing growth plate. Nat Cell Biol. 2005;7(7):698-705.

24. Megeney LA, Kablar B, Garrett K, Anderson JE, Rudnicki MA. MyoD is required for myogenic stem cell function in adult skeletal muscle. Genes Dev. 1996;10(10):1173-1183.

25. Rudnicki MA, Le Grand F, McKinnell I, Kuang $\mathrm{S}$. The molecular regulation of muscle stem cell function. Cold Spring Harb Symp Quant Biol. 2008;73:323-331

26. Dentice M, et al. Sonic hedgehog-induced type 3 deiodinase blocks thyroid hormone action enhancing proliferation of normal and malignant keratinocytes. Proc Natl Acad Sci U S A. 2007;104(36):14466-14471.

27. Charytonowicz E, Cordon-Cardo C, Matushansky I, Ziman M. Alveolar rhabdomyosarcoma: is the cell of origin a mesenchymal stem cell? Cancer Lett. 2009;279(2):126-136

28. Hawke TJ, Garry DJ. Myogenic satellite cells: physiology to molecular biology. J Appl Physiol. 2001;91(2):534-551.

29. Charge SB, Rudnicki MA. Cellular and molecular regulation of muscle regeneration. Physiol Rev. 2004;84(1):209-238.

30. Couteaux R. Early days in the research to localize skeletal muscle acetylcholinesterases.J Physiol Paris. 1998;92(2):59-62.

31. Brunelli S, et al. Nitric oxide release combined with nonsteroidal antiinflammatory activity prevents muscular dystrophy pathology and enhances stem cell therapy. Proc Natl Acad Sci US A. 2007;104(1):264-269.

32. Jerkovic R, Argentini C, Serrano-Sanchez A, Cordonnier C, Schiaffino S. Early myosin switching induced by nerve activity in regenerating slow skeletal muscle. Cell Struct Funct. 1997;22(1):147-153.

33. Gereben B, Zeold A, Dentice M, Salvatore D, Bianco AC. Activation and inactivation of thyroid hormone by deiodinases: local action with general consequences. Cell Mol Life Sci. 2008;65(4):570-590.

34. Barr FG. Gene fusions involving PAX and FOX family members in alveolar rhabdomyosarcoma. Oncogene. 2001;20(40):5736-5746.

35. Zhao J, et al. FoxO3 coordinately activates protein degradation by the autophagic/lysosomal and pro- teasomal pathways in atrophying muscle cells. Cell Metab. 2007;6(6):472-483.

36. Peeters RP, Friesema EC, Docter R, Hennemann G, Visser TJ. Effects of thyroid state on the expression of hepatic thyroid hormone transporters in rats. Am J Physiol Endocrinol Metab. 2002;283(6):E1232-E1238.

37. Imae M, Fu Z, Yoshida A, Noguchi T, Kato H. Nutritional and hormonal factors control the gene expression of FoxOs, the mammalian homologues of DAF-16. J Mol Endocrinol. 2003;30(2):253-262.

38. Pernitsky AN, McIntosh LM, Anderson JE. Hyperthyroidism impairs early repair in normal but not dystrophic mdx mouse tibialis anterior muscle. An in vivo study. Biochem Cell Biol. 1996;74(3):315-324.

39. McIntosh LM, Anderson JE. Hypothyroidism prolongs and increases mdx muscle precursor proliferation and delays myotube formation in normal and dystrophic limb muscle. Biochem Cell Biol. 1995;73(3-4):181-190.

40. Aranda A, Martinez-Iglesias O, Ruiz-Llorente L, Garcia-Carpizo V, Zambrano A. Thyroid receptor: roles in cancer. Trends Endocrinol Metab. 2009;20(7):318-324.

41. Collins CA, et al. Stem cell function, self-renewal, and behavioral heterogeneity of cells from the adult muscle satellite cell niche. Cell. 2005;122(2):289-301.

42. Montarras D, et al. Direct isolation of satellite cells for skeletal muscle regeneration. Science. 2005;309(5743):2064-2067.

43. Asakura A, et al. Increased survival of muscle stem cells lacking the MyoD gene after transplantation into regenerating skeletal muscle. Proc Natl Acad Sci U S A. 2007;104(42):16552-16557.

44. Cooper RN, Butler-Browne GS, Mouly V. Human muscle stem cells. Curr Opin Pharmacol. 2006;6(3):295-300.

45. Huang SA. Deiodination and cellular proliferation: parallels between development, differentiation, tumorigenesis, and now regeneration. Endocrinology. 2009;150(1):3-4.

46. Kester MH, et al. Large induction of type III deiodinase expression after partial hepatectomy in the regenerating mouse and rat liver. Endocrinology. 2009;150(1):540-545.

47. Dentice M, Ambrosio R, Salvatore D. Role of type 3 deiodinase in cancer. Expert Opin Ther Targets. 2009;13(11):1363-1373.

48. Yoshimura T, et al. Light-induced hormone conversion of $\mathrm{T} 4$ to $\mathrm{T} 3$ regulates photoperiodic response of gonads in birds. Nature. 2003;426(6963):178-181.

49. Larsen PR. Direct immunoassay of triiodothyronine in human serum. J Clin Invest. 1972; 51(8):1939-1949.

50. Maia AL, Kim BW, Huang SA, Harney JW, Larsen PR. Type 2 iodothyronine deiodinase is the major source of plasma T3 in euthyroid humans. J Clin Invest. 2005;115(9):2524-2533.

51. Yan Z, et al. Highly coordinated gene regulation in mouse skeletal muscle regeneration. J Biol Chem. 2003;278(10):8826-8836.

52. Christoffolete MA, et al. Mice with impaired extrathyroidal thyroxine to 3,5,3'-triiodothyronine conversion maintain normal serum 3,5,3'-triiodothyronine concentrations. Endocrinology. 2007; 148(3):954-960. 